\title{
Effect of Yogasanas and Suryanamaskar on Selected Physical, Physiological and Psychological Variables Among School Girls in Chennai, Tamil Nadu, India
}

\author{
A. Yuvaraj \\ Department of Physical Education, National Sports University, Imphal, Manipur
}

\begin{abstract}
The purpose of the study was to investigate the effect of yogasanas and suryanamaskar on selected physical, physiological and psychological variables among school Girls in Chennai, Tamil Nadu, India. To achieve the purpose of the study, 90 school girls randomly were selected from Chennai district level. Their age ranged between from 14 to 18 years. The subjects were divided into three equal groups of thirty subjects each. Group-I underwent yogasana, group-II underwent suryanamaskar and group-III acted as a control group. The duration of the experimental period for yogasana and suryanamaskar group is restricted to twelve weeks and the number of session per week confined to six days. For this study the following variables were selected as dependent variables. Physical variables: Flexibility. Physiological variables: BMI and Psychological variables: Anxiety, within the limitations and delimitations of this study, the following conclusions were drawn, it was concluded that there was significant improvement in flexibility due to yogasana and suryanamaskar comparing to control group and It was concluded that there was significant reduction in BMI, Anxiety due to yogasanas and suryanamaskar comparing to control group.
\end{abstract}

KEY WORDS: YOGASANAS, SURYANAMASKAR, PHYSICAL, PHYSIOLOGICAL, PSYCHOLOGICAL VARIABLES AND CHENNAI SCHOOL GIRLS.

\section{INTRODUCTION}

Yoga is considered as a full fledged science. The science of yoga consists of acquiring knowledge through observation and experiment. It is a science, which deals with the body and mind controlling the body through the practice of Yoga to achieve the rhythm of mind. The health and strength of the body and the mind are acquired, only when a state of equilibrium is attained whereby the body and the mind are balanced. Like all other arts, Yoga is

\section{ARTICLE INFORMATION}

Received 9th Oct 2020 Accepted after revision 25th Dec 2020 Print ISSN: 0974-6455 Online ISSN: 2321-4007 CODEN: BBRCBA

Thomson Reuters ISI Web of Science Clarivate Analytics USA and Crossref Indexed Journal

\section{Clarivate
Analytics}

NAAS Journal Score 2020 (4.31)

A Society of Science and Nature Publication,

Bhopal India 2020. All rights reserved.

Online Contents Available at: http//www.bbrc.in/

Doi: http://dx.doi.org/10.21786/bbrc/13.15/49 also a science as well as a philosophy too. As science is concerned with analyses Yoga too is bent on analysis. Yoga analyses the turbulent mind and shows the ways and means of reaching the ultimate goal of freedom. As any other science, yoga too conveys truth.

On a practical level, yoga keeps the body healthy the mind quite and pure, and self in beatitude. It is therefore a darsana. The practical aspect of yoga darsana conveys the artistic aspect of Yoga with its precision and beauty. The science of yoga works on physical, mental, emotional, psychic and spiritual aspects of a person, when imbalance is experienced at this level, the organs, muscles and nerves no longer function in harmony, rather they act in opposition to one another. Therefore, yoga aims at bringing the different bodily functions into perfect co-ordination so that they work for the good at the whole body. Therefore yoga develops the personality of an individual mentally, morally, spiritually and Intellectually. 
Asana: is the practice of physical postures. It is the most commonly known aspect of yoga for those unfamiliar with the other seven limbs of Patanjali's Yoga Sutra. The practice of moving the body into postures has widespread benefits; of these the most underlying are improved health, strength, balance and flexibility.

Suryanamaskar: an ancient Indian yoga is the art of solar vitalization. It is a complete meditative technique in itself as it includes Asanas, Pranayama, Mantras and Mudras. It has got three aspects: form, vital energy and rhythm. It is the easiest way for a person to get used to Yoga. It should be done along with chanting of mantras in every posture. In simple words, Suryanamaskar is a combination of 12 different postures, followed in a particular sequence with a specific breathing pattern. It helps an individual to vitalize and unblock the whole system. It reduces fat from almost all parts of the body, as it stretches each and every muscle and tones it.

Statement of the problem: The purpose of the study was to investigate the effect of yogasanas and suryanamaskar on selected physical, physiological and psychological variables among school girls.
Hypothesis: (1).It was hypothesized that there would be significant differences due to yogasanas and suryanamaskar on selected physical, physiological and psychological variables among school girls than the control group.

(2).It was hypothesized that there would be significant differences due to yogasanas on selected physical, physiological and psychological variables among school girls of yogasana group than the suryanamaskar group.

\section{METHODOLOGY}

To achieve the purpose of the study, 90 school girls were randomly selected from Chennai district level, Tamil Nadu, India. Their age ranged between from 14 to 18 years. The subjects were divided into three equal groups of thirty subjects each. Group-I underwent yogasana, group -II underwent suryanamaskar and group-III acted as a control group. For the period of twelve weeks and sex days in a week. The following variables were selected as dependent variables Physical variable: flexibility. Physiological variable: BMI and Psychological variables: Anxiety.

\section{Table 1. Computation of Analysis of Covariance of Flexibility}

\begin{tabular}{|c|c|c|c|c|c|c|c|c|}
\hline & YG & SMG & CG & SV & SS & $\mathrm{df}$ & MS & $\mathrm{F}$ \\
\hline \multirow[t]{2}{*}{ Pre test mean } & \multirow[t]{2}{*}{25.2} & \multirow[t]{2}{*}{22.80} & \multirow[t]{2}{*}{24.77} & B & 98.16 & 2 & 49.078 & \multirow{2}{*}{2.61} \\
\hline & & & & W & 1636.97 & 87 & 18.82 & \\
\hline \multirow[t]{2}{*}{ Post test mean } & \multirow[t]{2}{*}{28.76} & \multirow[t]{2}{*}{24.20} & \multirow[t]{2}{*}{25.17} & $\mathrm{~B}$ & 347.49 & 2 & 173.74 & $11.35^{*}$ \\
\hline & & & & W & 1332.33 & 87 & 15.31 & \\
\hline \multirow[t]{2}{*}{ Adjusted mean } & \multirow[t]{2}{*}{28.39} & \multirow[t]{2}{*}{24.78} & \multirow[t]{2}{*}{24.96} & $\mathrm{~B}$ & 241.36 & 2 & 120.68 & \multirow[t]{2}{*}{$9.70^{*}$} \\
\hline & & & & $\mathrm{W}$ & 1069.634 & 86 & 12.44 & \\
\hline
\end{tabular}

Table F ratio at 0.05 level of confidence for 2 nd and 87 (df) $=3.1$

Table 2. Scheffe's confidence interval test scores on flexibility

\begin{tabular}{|l|c|c|c|c|}
\hline & M & & \multirow{2}{*}{ MD } & \multirow{2}{*}{ RCI } \\
\cline { 1 - 3 } YG & SMG & CG & & \\
\hline 28.39 & 24.96 & - & $3.43^{*}$ & 2.27 \\
\hline 28.39 & - & 24.78 & 0.18 & 2.27 \\
\hline- & 24.96 & 24.78 & $3.61^{*}$ & 2.27 \\
\hline
\end{tabular}

*significant at .05 level of confidence

Results on Physical Variable Flexibility: As shown in table-I obtained F-value on the scores pre test means 2.61 that the random assignment of the subject was successful and their scores in flexibility. The analysis of post test means proud that the obtained $F$ value 11.35 was greater than the required value of 3.1to be significant at 0.05 level. Taking in to consideration of the pre test means adjusted post test means were done
Figure 1

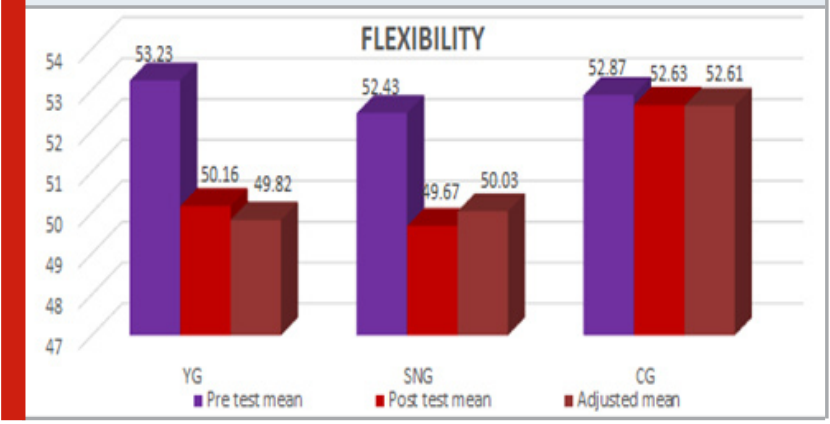

and the obtained $\mathrm{F}$ value 9.70 was greater than the required value of 3.1 and hence it was accepted that the yogasana and suryanamaskar practices significantly increased the flexibility. Since significance differences were recorded, the results were subjected to post hoc analysis using scheffe's confidence interval test. The result were presented in table-II. 
From the table-II, it was proved that there was significant differences between yogasana and suryanamaskar practices it was also interred that there was significant difference between yogasanas and control group. The mean values of control group and experimental group were graphically represented in Figure-1.

Discussion on the Findings of Flexibility: Flexibility was measured through sit-and reach test the result presented in table showed significances differences in the adjusted means, as they obtained F-value was greater than the required value the post hoc analysis of obtained adjusted means proved that there was significances differences existed between control group and yogasanas. It was also proved that there was significance difference between yogasana group and suryanamaskar group and control group.

Table 3. Computation of Analysis of Covariance of BMI

\begin{tabular}{|c|c|c|c|c|c|c|c|c|}
\hline & YG & SNG & CG & SV & SS & df & MS & F \\
\hline \multirow[t]{2}{*}{ Pre test mean } & \multirow[t]{2}{*}{22.11} & \multirow[t]{2}{*}{21.78} & \multirow[t]{2}{*}{21.22} & B & 12.23 & 2 & 6.117 & \multirow[t]{2}{*}{0.74} \\
\hline & & & & $\mathrm{W}$ & 721.05 & 87 & 8.29 & \\
\hline \multirow[t]{2}{*}{ Post test mean } & \multirow[t]{2}{*}{20.06} & \multirow[t]{2}{*}{20.34} & \multirow[t]{2}{*}{21.23} & B & 22.28 & 2 & 11.14 & $4.12^{*}$ \\
\hline & & & & $\mathrm{W}$ & 235.28 & 87 & 2.70 & \\
\hline \multirow[t]{2}{*}{ Adjusted mean } & \multirow[t]{2}{*}{19.87} & \multirow[t]{2}{*}{20.30} & \multirow[t]{2}{*}{21.46} & B & 39.82 & 2 & 19.91 & \multirow[t]{2}{*}{$3.24^{*}$} \\
\hline & & & & $\mathrm{W}$ & 73.679 & 86 & 0.86 & \\
\hline
\end{tabular}

Table F-ratio at 0.05 level of confidence for 2 nd and $87(\mathrm{df})=3.103$

Table 4. Scheffe's confidence interval test scores on BMI

\begin{tabular}{|l|c|c|c|c|}
\hline & M & & \multirow{2}{*}{ MD } & \multirow{2}{*}{ RCI } \\
\cline { 1 - 3 } YG & SMG & CG & & \\
\hline 21.46 & 19.87 & - & $1.59^{*}$ & 0.60 \\
\hline 21.46 & - & 20.30 & $1.16^{*}$ & 0.60 \\
\hline- & 19.87 & 20.30 & 0.43 & 0.60 \\
\hline
\end{tabular}

*significant at .05 level of confidence
Figure 2

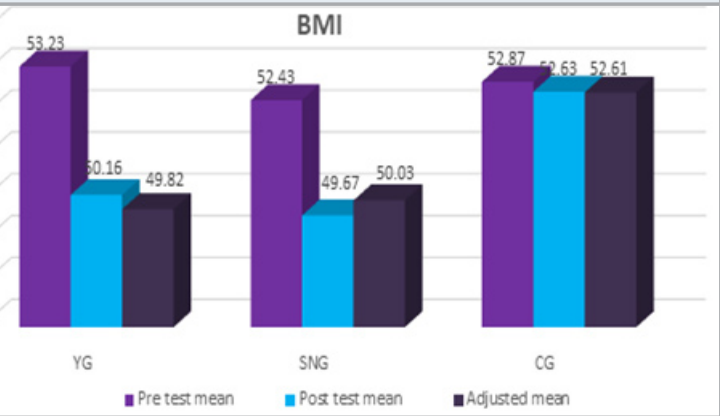

Table 5. Computation of Analysis of Covariance of Anxiety

\begin{tabular}{|c|c|c|c|c|c|c|c|c|}
\hline & YG & SNG & CG & SV & SS & df & MS & $\mathrm{F}$ \\
\hline \multirow[t]{2}{*}{ Pre test mean } & \multirow[t]{2}{*}{53.23} & \multirow[t]{2}{*}{52.43} & \multirow[t]{2}{*}{52.87} & B & 9.62 & 2 & 4.811 & \multirow[t]{2}{*}{0.20} \\
\hline & & & & W & 2056.20 & 87 & 23.63 & \\
\hline \multirow[t]{2}{*}{ Post test mean } & \multirow[t]{2}{*}{50.16} & \multirow[t]{2}{*}{49.67} & \multirow[t]{2}{*}{52.63} & B & 151.36 & 2 & 75.68 & $3.51^{*}$ \\
\hline & & & & $\mathrm{W}$ & 1873.80 & 87 & 21.54 & \\
\hline \multirow[t]{2}{*}{ Adjusted mean } & \multirow[t]{2}{*}{49.82} & \multirow[t]{2}{*}{50.03} & \multirow[t]{2}{*}{52.61} & B & 145.08 & 2 & 72.54 & \multirow[t]{2}{*}{$26.96^{*}$} \\
\hline & & & & W & 231.381 & 86 & 2.69 & \\
\hline
\end{tabular}

Table F ratio at 0.05 level of confidence for 2 nd and 87 (df) $=3.1$

\section{Results on Physiological Variable BMI}

As shown in table-III obtained F-value on the scores pre test means 0.74 that the random assignment of the subject were successful and their scores in BMI. The analysis of post test means proud that the obtained $F$ value 4.12 was greater than the required value of 3.1 to be significant at 0.05 level taking in to consideration of the pre test means adjusted post test means were done and the obtained $\mathrm{F}$ value 23.34 was greater than the required value of 3.1 and hence it was accepted that the yogasana and suryanamaskar practices significantly dicers the BMI. Since significance differences were recorded, the results were subjected to post hoc analysis using scheffe's confidence interval test. The results were presented in table-IV. 
From the table IV, it was proved that there was significant differences between yogasana and suryanamaskar it was also interred that there was significant difference between yogasana and control group. The mean values of control group and experimental group were graphically represented in Figure-2.

Discussion on the Findings of BMI: BMI was measured through the basic of Height/Wight the result presented in table showed significances differences in the adjusted means, As they obtained F-value was greater than the required value the post hoc analysis of obtained adjusted means proved that there was significances differences existed between control group and suryanamaskar group. It was also proved that there was significance difference between yogasana group and suryanamaskar group and control group.

\section{Results on Psychological Variable Anxiety}

As shown in table-V obtained F-value on the scores pre test means 0.20 that random assignment of the subject were successful and their scores in anxiety. The analysis of post test means proud that the obtained $\mathrm{F}$ value 3.51 was greater than the required value of 3.1 to be significant at 0.05 level taking in to consideration of

Table 6. Scheffe's confidence interval test scores on Anxiety

\begin{tabular}{|l|c|c|c|c|}
\hline & M & & \multirow{2}{*}{ MD } & RCI \\
\cline { 1 - 3 } YG & SMG & CG & & \\
\hline 52.61 & 49.82 & - & 2.79 & 1.05 \\
\hline 52.61 & - & 50.03 & 2.58 & 1.05 \\
\hline- & 49.82 & 50.03 & -0.21 & 1.05 \\
\hline
\end{tabular}

*significance at .05 level of confidence

Discussion on Reviews: These results are found to be in good agreement with the earlier works done by different researchers. Barshankar, et.al. (2003) examined the effect of yoga on cardiovascular function in subjects above 40 yrs of age after yogasana practices study state blood pressure and heart rate has significant improved, over a period of eight weeks. These results are found to be in good agreement with the earlier works done by different researchers. Reddy and Kumar (2001) conducted a study on yogasanas and aerobic dance and their effects on selected motor fitness components in girl subjects After yogasana and suryanamaskar practices study state agility, flexibility, blood pressure, BMI has significant improved, over a period of six weeks.

These results are found to be in good agreement with the earlier works done by different researchers. Lohan and Rajesh (2002) studied the effect of asanas and pranayama on physical and physiological components of boys between age group 12-16 years. After asana and pranayama practices study state agility, flexibility, blood the pre test means adjusted post test means were done and the obtained $F$ value 26.96 was greater than the required value of 3.1 and hence it was accepted that the yogasana and suryanamaskar practices significantly dicers the anxiety. Since significance differences were recorded, the results were subjected to post hoc analysis using scheffe's confidence interval test. The results were presented in table-VI.

From the table-VI, it was proved that there was significant differences between yogasana and suryanamaskar it was also interred that there was significant difference between yogasana and control group. The mean values of control group and experimental group were graphically represented in Figure-3.

Discussion on the Findings of Anxiety: Anxiety was measured through standard anxiety questionnaire the result presented in table showed significances differences in the adjusted means, as they obtained F-value was greater than the required value the post hoc analysis of obtained adjusted means proved that there was significances differences existed between control group and suryanamaskar group. It was also proved that there was significance difference between yogasana and suryanamaskar group control groups.

Figure 3

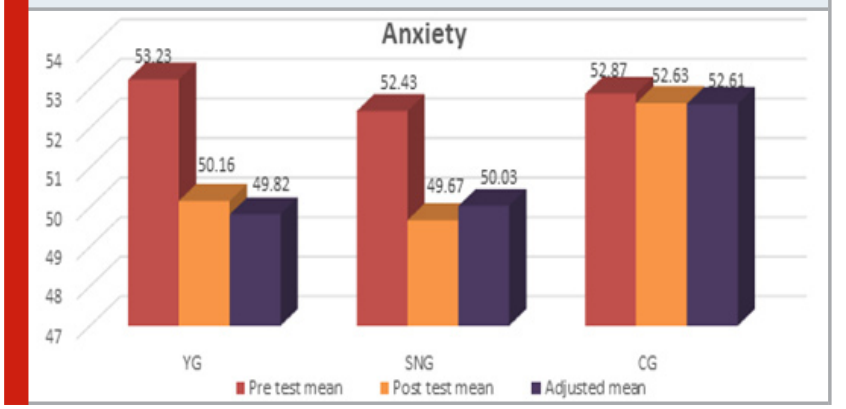

pressure, BMI has significant improved, over a period of eight weeks.

\section{CONCLUSION}

Within limitations and delimitations of this study, the following conclusions arrived at;

- It was concluded that there was significant improvement in flexibility due to yogasana and suryanamaskar when comparing to control group and

- It was concluded that there was significant reduction in BMI, Anxiety due to yogasanas and suryanamaskar when comparing to control group.

- It was concluded that there was significant reduction in Anxiety due to yogasanas and suryanamaskar when comparing to control group.

\section{REFERENCES}

Amutha, (2010) 'Effect of selected Yoga Programme on Anxiety, V02max and Flexibility', Journal of Physical 
Education and Sports Sciences, 2, pp.19-22.

Amuthambihai, S. (2018) 'Mpact Of Fast Suryanamaskar Practices On Anxiety And Self- Confidence Among School Girls', IJRAR, 5(4).

Anderson, L.B. (1994) 'Changes in Physical Activity are Reflected in Changes in Fitness During Late Adolescence' Journal of Sports Medicine and Physical Fitness, 34(4), pp.390-397.

Erikson, EH. (1967) Identity and the life cycle: Selected Papers. Psychological Issues Monographs. New York: International Universities Press.

Jyotsana, R. Bharshankar, et.al (2003) 'Effect Of Yoga On Cardiovascular System In Subjects Above 40 Years', Indian J Physiol Pharmacol, 47 (2),pp. 202-206

Mengistie alemayehu belay and reddy r.c and syam babu. (2013) 'the effects of combined aerobic and resistance exercise training on obese adults', north west ethopia, Research journal of recent sciences, 2(1), pp. 59-66.

Parthiban, V. (2019) 'Effect of Yogasanas and Surya
Namaskar on selected psychological variables among post graduate students', International Journal of Yogic, Human Movement and Sports Sciences, 4(2),pp.124127.

Taylor, C. B. et al.(1985) 'The Relation of Physical Activity and Exercise To Mental Health', public health rep,100(2), pp.195-202.

Uma.K et.al. (1989) 'The integrated Approach of yoga: a Therapeutic tool for mentally Retarded Children One Year Controlled Study', J. ment deficres, 3(33), pp. 41521.

Usha.Lohan and Dolly Rajesh. (2002) 'Effect of Asana and Pranayama on Physical and Physiological Components of Boys between Age Group 12-16 Years', Journal of sports and sports sciences, 25 (1), pp. 5056.

Yi-ching Huang and Robert Malina, M. (2002) 'Physical Activity and Health Related Physical Fitness in Taiwanese Adolescents', journal of physiological anthropology and applied human science,2(1), pp.1119. 